\title{
La colección arqueológica del Museo Sorolla
}

\author{
M. Pilar San nicolás Pedraz * \\ MONICA RUIZ BREMÓN **
}

El Museo Sorolla, de Madrid, conserva entre sus abundantes y diversos fondos una serie de piezas de carácter arqueológico, cuyo estudio acometemos en este trabajo '. Constituyen éstas el testimonio de un tipo de coleccionismo en el que no siempre se tiene en cuenta «la antigüedad - la autenticidad" de las piezas ${ }^{2}$, sacrificadas a veces en aras de la estética o de la simple curiosidad. De ahí que tanto desde el punto de vista temático como cronólogico su variedad sea grande, pese a no serlo su extensión - 21 piezas- y que comprenda desde la cultura púnicoebusitana hasta el mundo paleocristiano, desde el barro cocido hasta el mármol...

Esta breve pero interesante colección se halla casi en su totalidad inédita ${ }^{3}$, habiéndose tan sólo realizado un estudio monográfico de una de las piezas ${ }^{4}$ e incluyéndose como meras citas algunas de otras en las diferentes Guias ${ }^{5}$ del Museo, en general en razón de sus grandes dimensiones o de su llamativa ubicación.

* Departamento de Prehistoria e Historia Antigua de la UNED

** Universidad Complutense de Madrid.

Agradecemos las facilidades que nos ha proporcionado Don F. de Santa-Ana, Director del Museo Sorolla, para el estudio de estas piezas.

2 Santa-Ana, DE F., Guia del Museo Sorolla, Madrid 1980. pág. 13

3 El Catálogo de Escultura del Museo Sorolla, realizado por F. Santa-Ana y M. Ruiz Bremón, se encuentra actualmente pendiente de su publicación por el Ministerio de Cultura.

${ }^{4}$ Sotomayor, M., "Un fragmento de tapa de sarcófago paleocristiano en el Museo Sorolla de Madrid", Boletin de Seminario de Estudios de Arte y Arqueologia, XLVI 1980, págs. 233-239.

5 Pantorba, B. DE, Guia del Museo Sorolla, Madrid 1967; Gaya-Nuño, J. A., Historia y Guía de los Museos de España, Madrid 1968; SANTA-ANA, DE, F., op. cit., en nota 1. 
El principal problema que una colección de estas características presenta a la hora de su estudio es el de la ausencia de datos ciertos sobre la procedencia de las piezas. En efecto, la documentación del Museo no nos proporciona ningún dato exacto sobre la adquisición de las obras, con una sola excepción: en una carta dirigida por el Marqués de Viana a Sorolla se alude a "dos figuras" como procedentes de Cástulo ${ }^{6}$. Del resto de la colección sólo se puede dar por segura la procedencia del busto de Tanit de la Cueva de Es Cuieram (Ibiza) ${ }^{7}$ y ello en virtud de sus propias características tipológicas, no por conocerse la vía de obtención de esta importante pieza.

La colección es presentada siguiendo un criterio de catalogación por materias o procedimientos (escultura en barro cocido y piedra, cerámica, vidrio, monedas y hierro) y, dentro de ellos, cronológicamente. El número por el que se citan, en espera de la aparición del Catálogo, corresponde al de los Inventarios del Legado Funcional del Viuda de Sorolla (1929 y 1930).

\section{TERRACOTAS}

1. Núm. Inv. 900; barro cocido; $0,10 \times 0,09 \times 0,06 \mathrm{~m}$

Busto de la diosa Tanit ${ }^{8}$, de forma acampanada, hueca, de base abierta, sección elíptica. La cabeza de proporciones más grandes que el cuerpo, tocada con un alto y liso Kalathos del que asoma el cabello inflado cayendo en dos trenzas lisas a ambos lados de la cara. Rostro borroso, pero posiblemente de influencia helenistica aunque tratado con cierto arcaismo. El cuerpo va formado por dos grandes alas plegadas sobre el pecho, a modo de manto, que se unen en la parte central inferior, dejando un espacio triangular decorado con una flor de loto.

${ }^{6}$ La carta fechada en Madrid el 19 de enero de 1916, dice textualmente: «... ahí van dos figuras bastante interesantes de las ruinas de Cástulo, que acaban de descubrirse. En ningún lugar estarán mejor que en el precioso jardin de $V$...".

'Esta última ha sido incluida por M. P. San Nicolás en su "Nota sobre la tipología del Santuario de Es Cuieram (Ibiza)", AEspA, 56, 1983, pág. 240, fig. 18.

${ }^{8}$ AUBET, M. E., "Algunos aspectos sobre la iconografía púnica: las representaciones aladas de Tanit", Rev. Univ. Complutense XXV, 101 (Hom. Garcia y Bellido II), 1976, págs. 61-82. 
Está fabricada con molde bivalvo, la parte posterior lisa. Arcilla ocre claro. Incompleta en su parte inferior izquierda, apreciándose concreciones calcáreas en su superficie.

Procedencia: Santuario de la Cueva de Es Cuieram (Ibiza).

Esta figura se puede incluir en el tipo 16 de la clasificación de figuras acampanadas de la Cueva de Es Cuieram de M. E. Aubet ${ }^{9}$.

Cronología: Entre los siglos IV y el II a. C.

Bibliografía: SANTA-ANA F., op. cit. en nota 1, pág. 50; SAN NiCOLÁS M. P., op. cit., en nota 7.

2. Núm. Inv. 916; barro cocido, $0,07 \times 0,04 \times 0,04 \mathrm{~m}$

Cabeza de figura femenina, facciones influídas por el arte griego clásico. Ojos con párpados, cuya caida nos recuerda al dramatismo de la escuela de Scopas, naríz recta, boca pequeña y labios gruesos. Cabello ondulado y recogido en un alto moño, en las orejas pendientes circulares con una roseta de ocho pétalos. Cuello largo (fig. 1).

Está fabricada con molde bivalvo, la parte posterior lisa. Arcilla ocre claro. Incompleta.

Procedencia: Desconocida.

Esta clase de figuras es característica de Tanagra (Beocia) cuyo tipo se extendió a partir del siglo Iv a.C. por todo el Mediterráneo ${ }^{10}$. El peinado es semejante al de algunas figuras siciliotas del siglo iv a. C. ${ }^{11}$.

Cronología: Finales del siglo IV o III a. C.

Bibliografia: SANTA-ANA F., op. cit., en nota 1.

\section{ESCULTURA}

3. Núm. Inv. 1433; mármol blanco; $1,60 \times 0,70 \times 0,40 \mathrm{~m}$

Togado acéfalado altoimperial (fig. 2).

Falta la cabeza, móvil, los antebrazos, la parte inferior con las puntas de los pies y grandes fragmentos en el dorso. Partido transversalmente

${ }^{9}$ Aubet, M. E., “La cueva d'Es Cuyram (Ibiza)», Pyrenae 4, 1968, pág. 19. Y en Publicaciones Eventuales 15. Univ. Barcelona, 1969, pág. 19; AUBET, M. E., "El Santuario de Es Cuiram", Trabajos del Museo Arq. de Ibiza 8, Ibiza 1982, pág. 22.

10 Mollard-Besques, S., Les terres cuites grecques, Paris 1963, pág. 99.

1 Higgins, R. A., Catalogue of the terracottas in the department of greek, and roman antiquities, British Museum, Oxford 1969, págs. 318-319, lám. 161, núms. 173-179. 


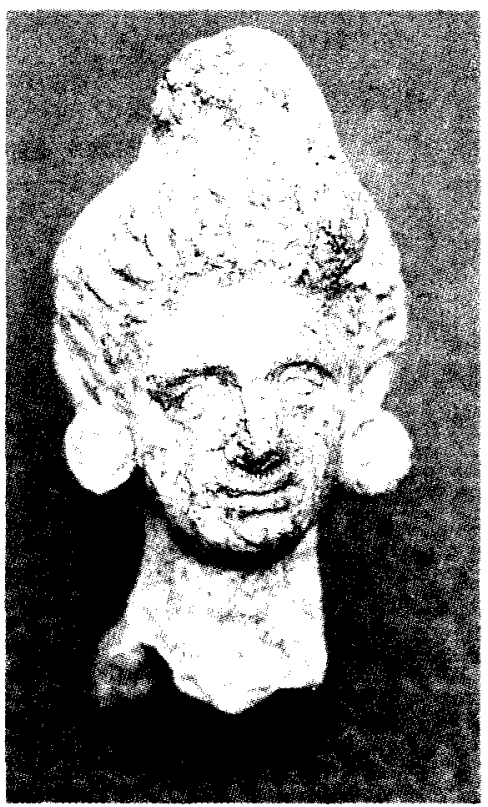

Fig. 1. Cabeza de figura femenina en terracota.

a la altura de la cadera, ha sido restaurado con cemento y una grapa de hierro por la parte posterior. Otra grapa de hierro penetra por el orificio del cuello.

Procedencia: Desconocida. Aunque de probable origen andaluz, no creemos que se trate de una de las "dos figuras" de Cástulo que el Marqués de Viana envía a Sorolla: su envergadura e importancia hubieran dado lugar, en su carta a otro título más expresivo que el de simple "figura".

Entre sus paralelos en la Península el más cercano es el togado de Mérida ${ }^{12}$, donado al M.A.N. por el Marqués de Monsalud en 1930 y que A. García y Bellido considera de taller bético y época flavia ${ }^{13}$.

12 Navasques y Juan, J. M., "Colección de Antigüedades que pertenecieron a! Sr. Marqués de Mosalud", Museo Arqueológico Nacional. Adquisiciones. 1931. Madrid 1931, pág 4, lám. 1, núm. 148.

13. Garcia y Bellido, A., Esculturas romanas de España y Portugal, Madrid 1949, núm 215; lám. 157. 


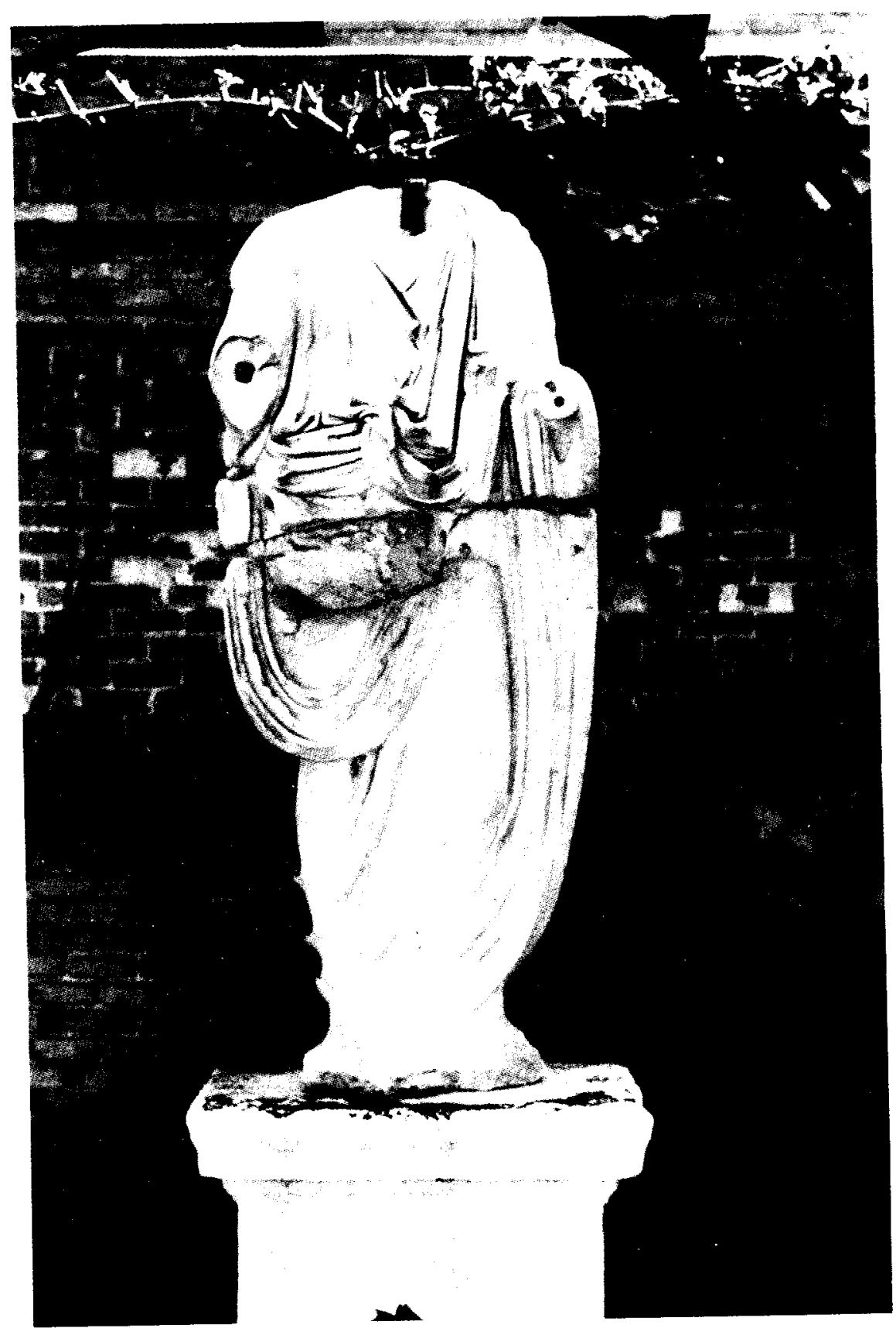

Fig. 2. Togado acefalo altoimperial en marmol. 
Cronología: Siglo I d. C.

Bibliografía: SANTA-ANA, F., op. cit., en nota 1, pág. 38.

4. Núm. Inv. 1006; mármol blanco; $0,18 \times 0,115 \times 0,055 \mathrm{~m}$

Hermes báquico barbado. El cabello ceñido con diadema de pámpanos, cae en bucles regulares rodeando las mejillas y termina en ondas que se prolongan a ambos lados de la cara hasta el arranque de los hombros. El rostro, de rasgos arcaizantes, muestra una nariz recta en perfil desde la frente y un ligero rictus de sonrisa en los labios, rodeados por abundante bigote. Este y la perilla se representan por medio de volutas simétricas hacia el exterior, disponiéndose la barba en seis tirabuzones verticales que disminuyen de longitud en los extremos (fig. 3).

Bien conservado en general, aunque amarillento el mármol y algo borroso el relieve de los ojos.

Procedencia: Desconocida.

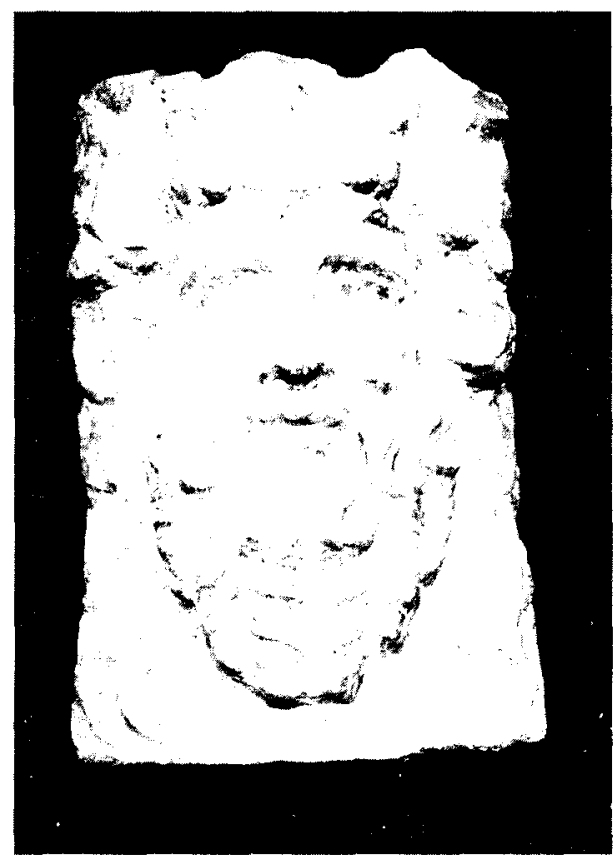

Fig. 3. Hermes báquico barbado en mármol. 
Entre los numerosos paralelos de esta pieza pueden citarse, entre otros, el Hermes de Nyon ${ }^{14}$ por sus semejanzas formales, el doble del Museo Nazionale Romano ${ }^{15}$, de época adrianea, y, en la Península, el procedente de Ampurias ${ }^{16}$, el de Cartagena, en el Museo Arqueológico de Murcia ${ }^{17}$, o el del Museo Arqueológico de Barcelona ${ }^{18}$, todos ellos de estilo arcaizante y rasgos serenos en la interpretación del rostro del dios.

Cronología: Siglos $1-11$ d. C.

Bibliografía: SANTA-ANA, F., op. cit., en nota 1, pág. 45.

5. Núm. Inv. 115; piedra caliza; $0,43 \times 0,15 \times 0,10 \mathrm{~m}$

Figura femenina. En pie, flexiona ligeramente su rodilla derecha, avanzando el pie contrario. Viste túnica ceñida bajo el pecho e himation plegado por delante y sostenido sobre el antebrazo izquierdo ${ }^{19}$. El cabeIlo, peinado en bandas rodeando el rostro y recogido en la nuca (fig. 4). Falta el brazo derecho y la mano izquierda, así como el ángulo inferior derecho de la túnica. La piedra muy sucia y golpeada en varias zonas. La figura se encuentra adosada en cemento a un capitel renacentista.

Procedencia: Desconocida, aunque bien podría tratarse aqui de una de las «figuras» de Cástulo.

Paralelos muy próximos a estas piezas pueden considerarse; la Livia del Musei Nazionale dei Nápoles ${ }^{20}$ y la Termis del museo Nacional de Atenas ${ }^{21}$; la figura de Delfos ${ }^{22}$ o la de Roma ${ }^{23}$. Igualmente se acerca a la de Zian (Túnez) ${ }^{24}$ y la de Utica ${ }^{25}$ entre otras muchas.

14 Esperandieu, E., Recueil General des Bas-reliefs de la Gaule Romaine, París 1955, V. 14; pág. 49, lám. LVI.

${ }_{15}$ Museo Nazionale Romano. Le sculture, Roma 1979. V.I, 2; núm. 30, págs. 31-2.

16 Almagro BasCH, M., "Una nueva cabeza de Hermes báquico hallada en Ampurias", AEspA, 1953, XXVI, págs. 217-220.

17 BalIL, A., "Esculturas romanas de la Península lbérica. IV", Studia Archeologica 68, 1981, págs. 12-13, núm. 65 , lám. IV 3.

is SerRa Rafols, J. C., "Hermes del Museo Arqueológico de Barcelona", Memorias de los Museos Arqueológicos Provinciales, VIII, 1947, pág. 80, V. lám. XXVI, 5.

19 Se trata del Himation tipo IV de la clasificación de RePOND, J., Les secrets de la draperie antique, París 1931.

${ }^{20}$ REPOND, J., op. cit. en nota 19 , pág. 84 , núm. 2.

21 REPOND, J., op. cit, en nota 19, pág. 82, fig. 64.

22 REINACH, S., Repertoire de la Statuaire Grecque et Romaine, Paris 1904; V.III, pág. 192, núm. 2 .

${ }^{23}$ ReINACH, S., op. cit., en nota 22, V.III, pág. 200, núm. 9.

${ }^{24}$ ReINACH, S., op. cit., en nota 22 , V.II, pág. 673 , núm. 7.

${ }^{25}$ Reinach, S., op. cit., en nota 22, V.II, pág. 675, núm. 10. 


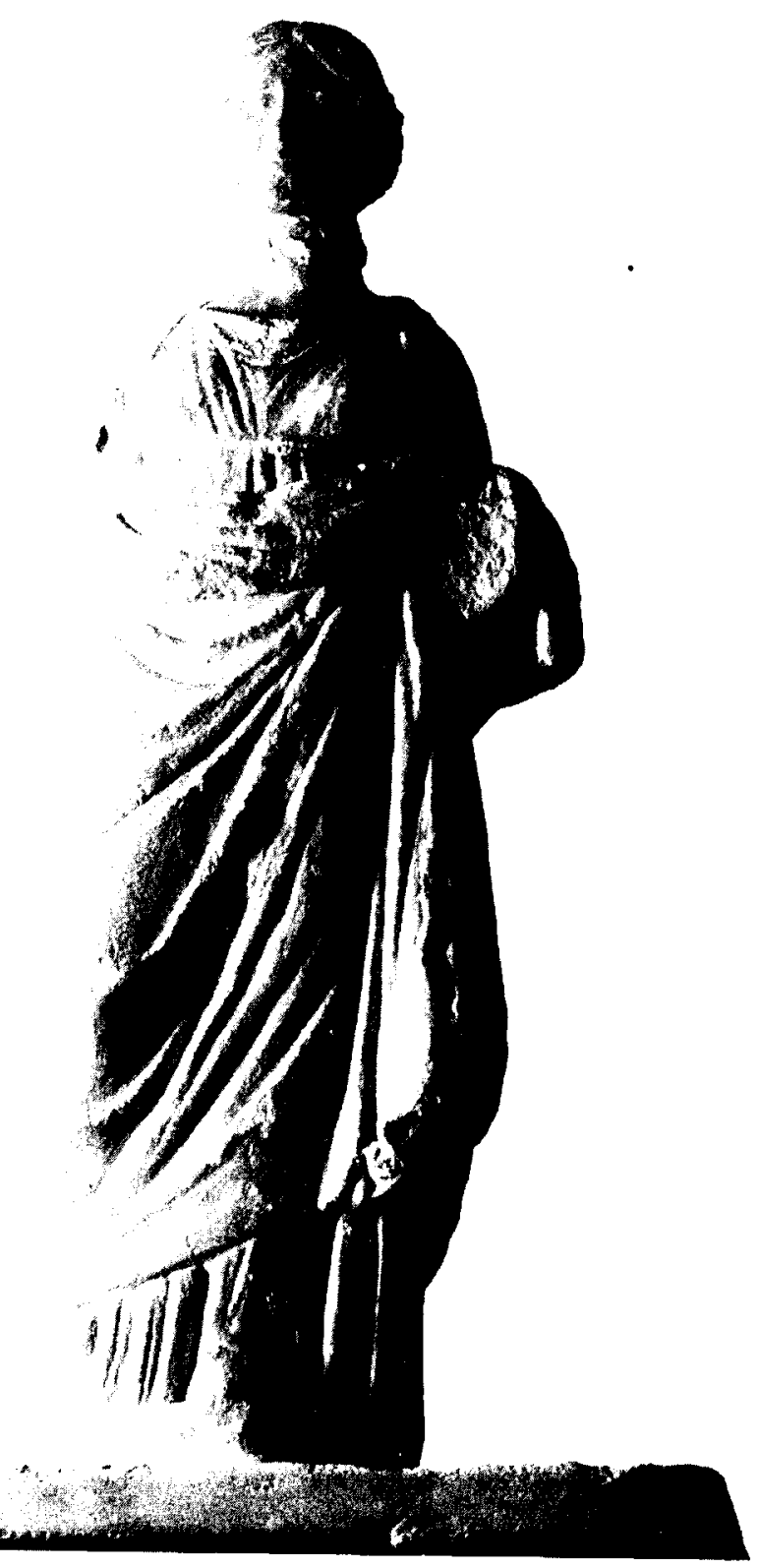

Fig. 4. Figura temenina en piedra. 
Cronologia: Siglos I-II d. C.

Bibliografia: SANTA-ANA, F., op. cit., en nota 1, pág. 76.

6. No consta en los inventarios; piedra caliza; $0,52 \times 0,30 \times 0,17 \mathrm{~m}$

Torso de Sileno, con parte de las piernas y mitad inferior de la cabeza, barbada. Viste túnica corta que deja al descubierto su hombro derecho y se anuda bajo el vientre. El cuerpo de contextura blanda y algo obeso, se trasluce bajo las ropas, para las que se ha empleado profusamente, como en la barba, la técnica del trépano. Avanzaba el Sileno la pierna derecha, cargando el peso del cuerpo en la cadera contraria (fig. 5).

Faltan los antebrazos, el brazo izquierdo, las piernas a partir de las rodillas y la cabeza. La piedra se encuentra muy afectada por la intemperie y con manchas de pintura negra en la parte inferior.

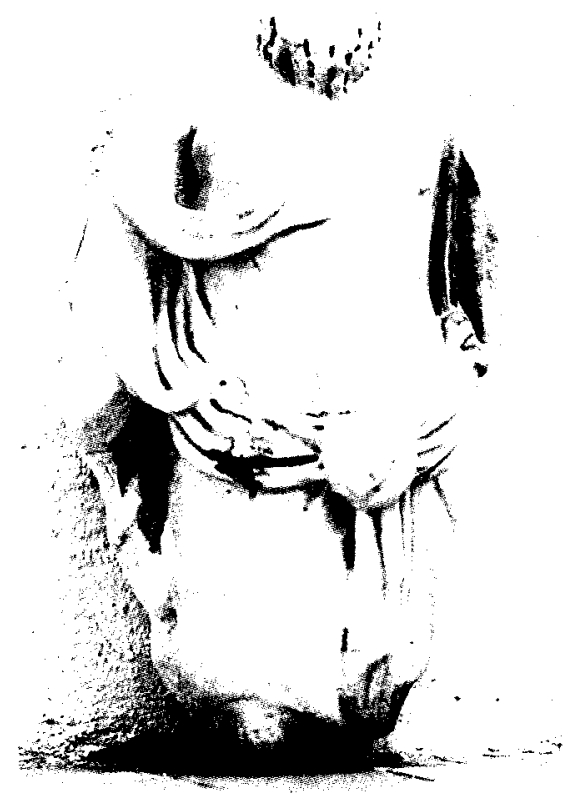

Fig. 5. Torso de Sileno en piedra. 
Procedencia: Desconocida ${ }^{26}$.

Un paralelo exacto de esta pieza lo encontramos en el Sileno del Museo Británico procedente de Aix ${ }^{27}$.

Cronología: Siglo III d. C.

Bibliografía: Inédito.

7. Núm. Inv. 1061; mármol blanco; $0,27 \times 0,20 \times 0,035 \mathrm{~m}$

Estela dedicada a Mercurio. Un grueso reborde protege el bajorrelieve con la figura del dios en el centro. Desnudo, porta una chlamide sobre el hombro y antebrazo izquierdos; se cubre con petaso y porta taloneras aladas; en la mano derecha, doblado el antebrazo en ángulo recto, lleva un saquito de dinero y, en la izquierda, apoyado sobre el hombro, el caduceo. Semioculto entre sus piernas y de perfil hacia la derecha, un carnero, que vuelve la cabeza en dirección al dios (fig. 6).

Bien conservada la figura, a excepción de un golpe en la rodilla derecha.

El marco, muy deteriorado y a falta del ángulo inferior izquierdo. Algo sucio el mármol.

Procedencia: Desconocida.

Desde el punto de vista estilístico, si bien a falta de algunos elementos iconográficos, esta pieza tiene un paralelo muy próximo en un exvoto con la historia de Hylas conservado en el Capitolio ${ }^{28}$. También se puede relacionar con los relieves de un altar de Bonn ${ }^{29}$ y de un bloque procedente de Seltz ${ }^{30}$. En cuanto a sus paralelos iconográficos, numerosísimos, cabe citar el altar de Trèves, procedente de Ehrang ${ }^{31}$, en el Museo de Stuttgart ${ }^{32}$, el de Boulogne ${ }^{33}$ y el de Picardie ${ }^{34} \ldots$ por su cronología, se acerca, finalmente, a tres estelas recogidas por E. Esperandieu ${ }^{35}$ en-

${ }^{26}$ Podría tratarse de la segunda pieza procedente de Cástulo.

${ }^{27}$ ReINACH, S., op. cit., en nota 22, V.II, pág. 52, núm. 6.

28 ReINACH, S., op. cit., en nota 22, V.III, pág. 191.

${ }^{29}$ Esperandieu, E., op. cit., en nota 14, V.11, pág. 96, núm. 7780.

${ }^{30}$ Esperandieu, E., op. cit., en nota 14, V.7, pág. 183, núm. 5562

${ }^{11}$ Hettner F., Die Römischen Steindenkmäler, Trier 1983, págs. 18-20.

32 Esperandieu. E.. Recueil General des Bas-Reliefs, estatues et bustes de la Germanie Romaine, París 1931, pág. 390, núm. 616.

${ }^{33}$ Esperandieu, E., op. cit., en nota 14, V.5, pág. 185, núm. 3976

${ }^{34}$ Esperandieu, E., op. cit., en nota 14, V.5, pág. 161, núm.3929.

35 Esperandieu, E., op. cit, en nota 14, V.4, pág. 224, núm. 3143; V.8, pág. 14, núm. 5908; V. 10, pág. 184 , núm. 7547. 


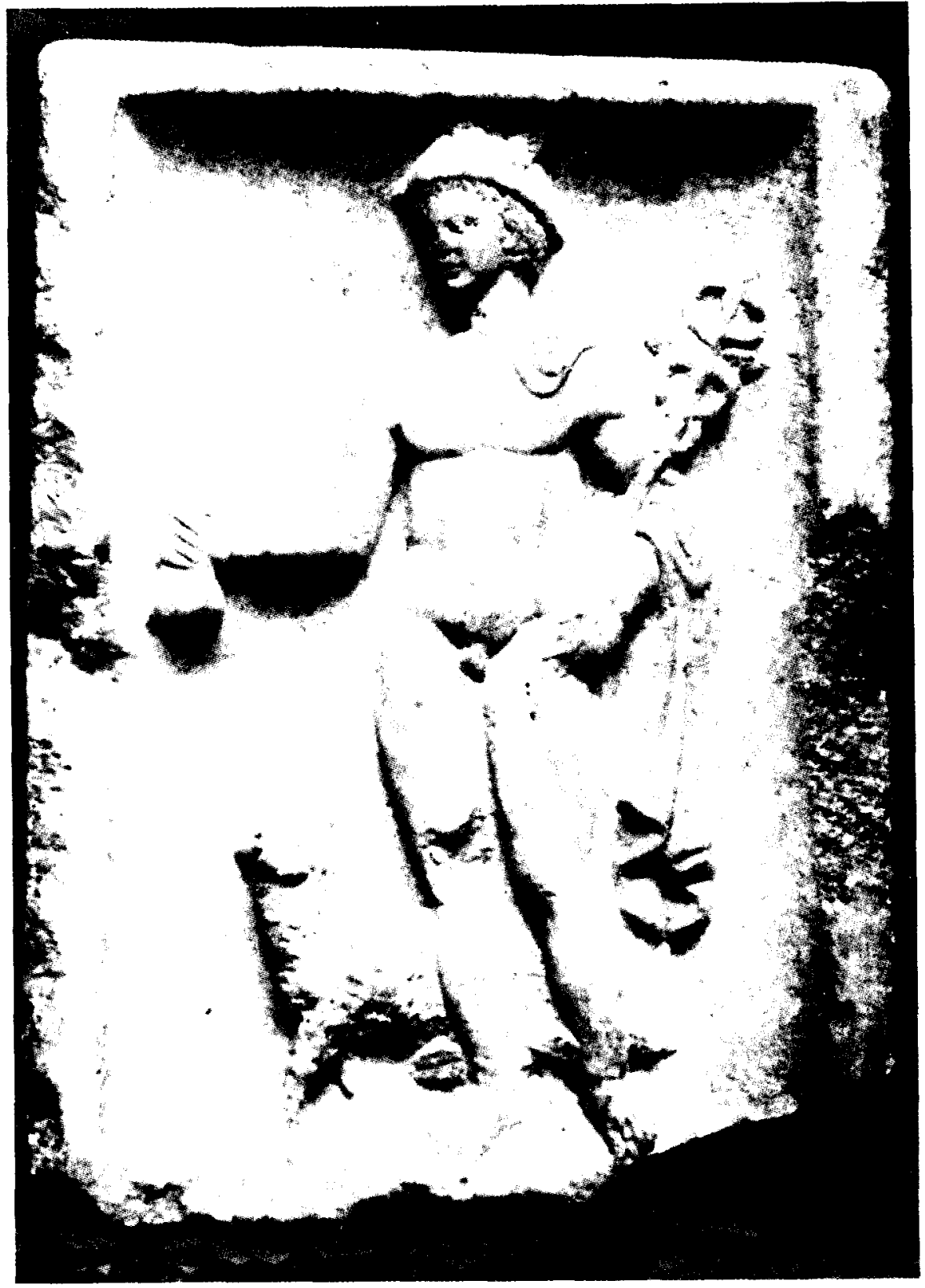

Fig. 6. Estela de Mercurio, en marmol. 


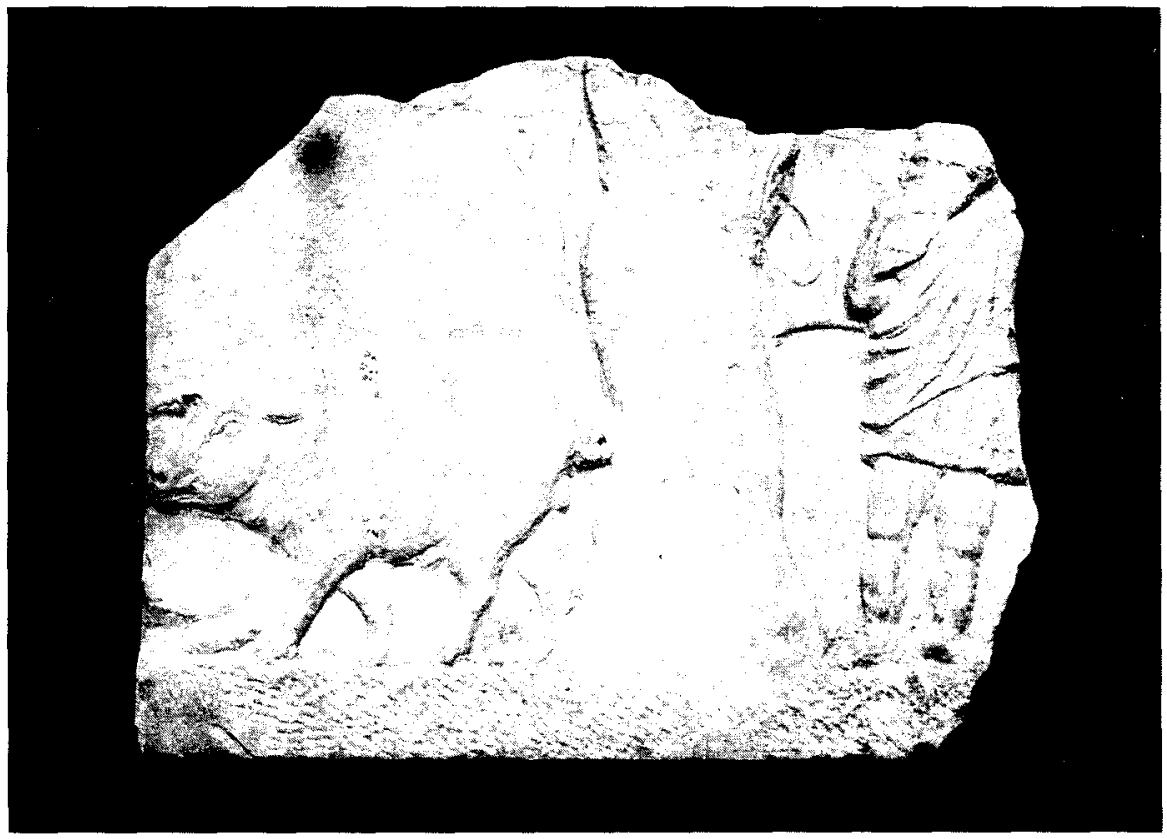

Fig. 7. Relieve con escena pastoril, en mármol.

tre las que destaca, en la segunda la representación del carnero, idéntica a la de nuestra pieza.

Cronologia: Siglo III d.C.

Bibliografia: SANTA ANA, F. op. cit., en nota 1, pág. 45.

8. Núm. Inv. 1431; mármol blanco; $0,37 \times 0,48 \times 0,04 \mathrm{~m}$

Relieve con escena pastoril. De izquierda a derecha y en estilo narrativo, un pastor de pie, con túnica corta y manto terciado sobre el hombro izquierdo, soplando una siringa; un alcornoque del que cuelga un zurrón; un cerdo avanzando de perfil a la derecha; una bellota en la mano izquierda del anterior $y$, finalmente, parte de la cola de un perro, también de perfil a la derecha (fig. 7). 
Pieza incompleta por los extremos laterales y superior. Algo desgastada la piedra. En el dorso liso, un orificio cuadrangular.

Procedencia: Desconocida.

Pieza singular que probablemente formaba parte de un sarcófago romano bajoimperial, con la representación de Orfeo como pastor. El tema, que pronto es adaptado a la iconografía cristiana del Buen Pastor ${ }^{36}$, ya se encuentra en el mundo funerario pagano desde el siglo 1 y III d.C. ${ }^{37}$.

Asi pues, con todos o algunos de los elementos iconográficos aqui presentes, la pieza del Museo de Sorolla se relaciona con los sarcófagos paleocristianos del Museo Vaticano ${ }^{38}$, del Cementerio de San Sebastián en Roma ${ }^{39}$, del Museo Capitolino ${ }^{40}$, de San Salvatore in Vescovio ${ }^{41}$ de la Basilica de Sta. Cecilia ${ }^{42}$ y Museo del Camposanto Teutónico ${ }^{43}$, si bien carente del simbolismo cristiano que reflejan éstos.

Cronologia: Siglo III d.C.

Bibliografía: Inédito.

9. No consta en los inventarios; mármol blanco; $0,37 \times 0,43 \mathrm{~m}$

Fragmento de la tapa de un sarcófago paleocristiano, con la cabeza de un apóstol barbado a la izquierda y una escena del ciclo de Jonás a la derecha: Jonás reposando bajo la calabacera. Ambas escenas estan separadas por una columnilla rematando en un lirio, Jonás, sentado con la pierna derecha flexionada, lleva la mano derecha sobre su cabeza; el brazo izquierdo cae, extendido como la pierna, a lo largo del cuerpo. Ante él, la boca del monstruo marino que acaba de arrojarlo a la tierra (fig. 8).

Muy desgastado el relieve, incompleto y partido en dos fragmentos. Se encuentra adosado a uno de los muros exteriores de la casa.

36 Panyagua, E. R., La figura de Orfeo en el arte griego y romano, Salamanca 1967. págs. 57-8: refiriéndose a un «missorium» del siglo $\mathrm{N}$ de Cesena (Italia), indica que el tema del pastor con siringa, aquí reflejado, no es todavia el del Buen Pastor, aunque dará lugar a él.

37 Panyagua, E. R., op. cit., en nota 36, pág. 67.

38 Deichman, F. W., Repertorium der Christlich-antiken sarkophage, Wiesbaden 1967, núm. 76, lám. 23 y núm. 148, lám 34.

39 Deichman, F. W. op. cit. en nota 38, núm. 239, lám. 53.

40 WILPERT, G., I sacorfagi cristiani antichi, Roma 1929. I, LXXV,1.

4 WILPERT, G., op. cit., en nota 40, I, LXX,2, obra del siglo IV.

42 WILPERT, G., op. cit, en nota $40,1, L X X, 1$, obra del siglo III.

43 WILPERT, G., op. cit., en nota 40, I, LXX,3, obra del siglo IV. 


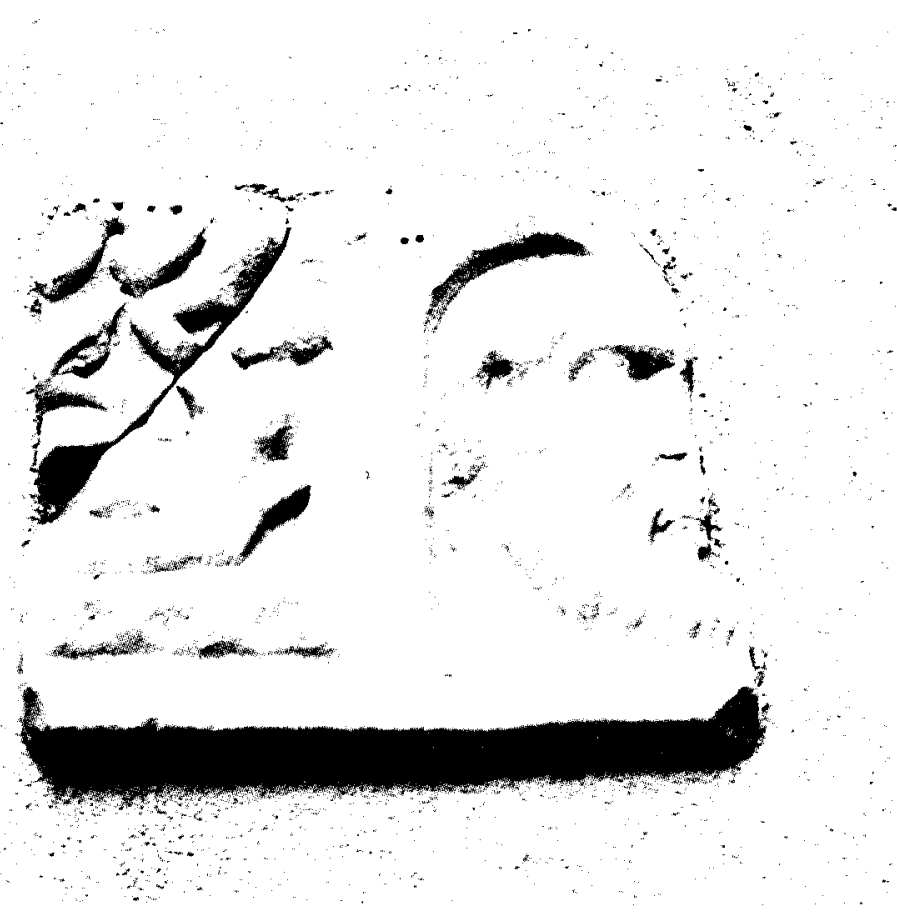

Fig. 8. Fragmento de la tapa de un sarcófago paleocristiano.

\section{Procedencia: Desconocida ${ }^{44}$.}

Según M. Sotomayor ${ }^{45}$ su único paralelo en la Península, hasta el momento, to constituye el fragmento de Alcaudete, publicado por A. Recio ${ }^{46}$. Fuera de la Península, lo son el del cementerio de San Calixto $y$ el de Lyon ${ }^{47}$, entre otros.

Cronologia: Años 325-335 d.C.

Bibliografia: SANTA-ANA, F., op. cit., en nota 1, pág. 38; SOTOMAYOR, M. op. cit., en nota 3 .

${ }^{44}$ M. Sotomayor, apunta la posibilidad de que proceda de Andalucia, quizás de la zona cordobesa.

${ }_{45}$ Sotomayor, M., op. cit., en nota 3, pág. 234.

${ }^{46}$ ReCIO, A., "Una tapa de sarcófago constantiniano hallada en Alcaudete", Antonianüm, 43, 1968, págs. 21-52.

${ }^{47}$ Sotomayor, M., op. cit., en nota 3, pág. 235 y notas 12-13. 
CERÁMICA

10. Núm. Inv. 897; barro cocido; $0,02 \times 0,08 \times 0,11 \mathrm{~m}$

Lucerna ática de pico pequeño, borde curvo y fondo cóncavo, con el agujero de la mecha ocupando prácticamente toda la superficie del pico. El tubo central está casi al nivel del borde, no tiene asas, y el barniz negro esta aplicado en toda la superficie excepto un círculo reservado alrededor del borde.

Arcilla ocre claro. Barniz negro en la superficie. Completa.

Procedencia: Desconocida ${ }^{48}$.

Esta lucerna es del tipo $22 \mathrm{~A}$ del Agora, fechada en el año 500 hasta el 460 a.C. ${ }^{49}$. También la encontramos en Ibiza ${ }^{50}$.

Cronologia: Entre los años 500-460 a.C.

Bibliografia: Inédita.

11. Núm. Inv. 899; barro cocido; $0,12 \times 0,05 \mathrm{~m} \varnothing$

Ungüentario de cuello largo y cilindrico, boca circular plana, cuerpo de tendencia globular y pie corto.

Procedencia: Desconocida.

Corresponde a la B IV de E. Cuadrado, que cronológicamente se situa del año 180-100 a.C. ${ }^{51}$. Este tipo de ungüentarios se encuentra bastante difundido por el mundo púnico, concretamente en lbiza conocemos seis ejemplares que se conservan en el Museo Municipal de Valencia de la colección Marti Esteve ${ }^{52}$ y otros tres en el Museo Episcopal de Vic. (Barcelona) ${ }^{53}$.

${ }^{48}$ Posiblemente proceda de lbiza como las piezas núms. 1 y 11

${ }^{49}$ Howland, S., Greek lamps and their survivals, the Athenian Agora, vol. IV, Princeton 1950, págs. 52 y 53, fig. 7, lám. 35, núms. 193-194.

50 SANCHEZ-Fernández, C., "La cerámica ática de lbiza en el Museo Arqueológico Nacional', Trab. de Preh. 38, 1981, pág. 296, fig. 6,8

51 CuAdRAdo, E., "Ungüentarios cerámicos en el mundo ibérico. Aportación cronológica", AEspA 50-51, 1978, Pág. 394.

52 VENTO MiR, E., Colección Martí Esteve. Materiales procedentes de Ibiza. Excmo. Ayuntamiento de Valencia, Arqueologia 4, Valencia 1985, pág. 44, figs. 12-13, M.E.-El/1, $9-11,14$ y 17.

53 San Nicolás Pedraz, M. P., "Complemento al catálogo de la cerámica de lbiza", Trab. de Preh. 42, 1985, págs. 297-299, núms. 40-42. 
Cronologia: Siglos III-II a.C.

Bibliografía: Inédito.

12. No consta en los inventarios; barro cocido; $0,19 \times 0,14 \times 0,07 \mathrm{~m}$

Lucerna de dos picos de terminación redondeada rematados asimismo en su arranque por surcos redondeados. Asa de cinta. La orla muy amplia muestra decoración de yedra, acanto y helecho realizada, al menos en parte, a la barbotina. El pequeño disco, con agujero central, aparece enmarcado por un resalte (fig. 9).

Arcilla ocre claro anaranjado, con restos de barniz negro tanto por el exterior como por el interior. Fragmentada e incompleta, le falta parte de un pico y del disco.

Procedencia: Desconocida.

Este tipo de lucernas es considerado por D. M. Bailey como la última manifestación de la lámpara helenística moldeada de fabricación itálica, y

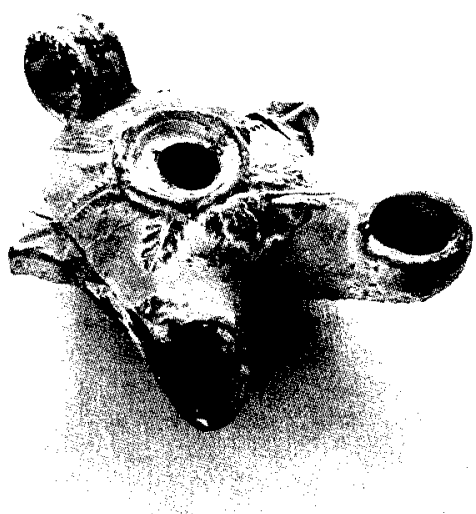

Fig. 9. Lucerna de dos picos con decoración vegetal. 
seria fechable en la segunda mitad del siglo । a.C. ó principios del 1 d.C. ${ }^{54}$. La encontramos también en el Santuario de Juno en Gabii ${ }^{55}$. Cronologia: Segunda mitad del siglo । a.C. o principios del I d.C. Bibliografia: Inédita.

13. Núm. Inv. 780; barro cocido; $0,24 \times 0,08 \mathrm{~m}$

Fragmento de borde en forma de pico de pato de una cerámica ibérica, posiblemente de una vasija globular, con decoración de círculos concentrados y bandas redondeando la base del borde de color ocre vinoso.

Arcilla ocre claro. Incompleta.

Procedencia: Desconocida.

Esta clase de cerámica se encuentra ampliamente difundida por SE español, como la Alcudia de Elche ${ }^{56}$ y por algunas regiones andaluzas, Cástulo ${ }^{57}$.

Cronologia: A partir del siglo Iv a.C. hasta el IV d.C.

Bibliografia: Inédito.

14. Núm. Inv. 780; barro cocido; 0,07 y $0,12 \mathrm{~m}$

Fragmento de galbo de una cerámica ibérica con decoración a base de circulos concentricos y semicírculos concentricos invertidos con respecto a los anteriores, ambos de color ocre vinoso, atravesados en su centro por dos líneas paralelas.

5Alley, D. M., Catalogue of the Lamps in the British Museum, Londres 1975, paigs. 326, 345-346, núms. Q.729-Q.732, lám. 135.

55 Elvira, M. A., "Lucernas", en M. Almagro Gorbea (ed.), El Santuario de Juno en Gabii. Roma 1982, pág. 521, núms. 47-48, lám. LXXII.

56 Ramos Fernandez, R., "Precisiones para la clasificación de la cerámica ibérica". Lvcentum I, 1982, págs. 117-125, en donde se recoge toda la bibliografia sobre ceramica ibérica de la Alcudia de Elche (Alicante).

57 Blazouez, J. M., “Cástulo I”. Acta Arqueológica Hispánica 8, 1975, págs. 265-268, fig. 156, 1; Idem "Castulo II", E.A.E. 105, 1979, pág. 27, fig. 18 y lám. IV, 4; BLAZQUEZ, J. M., Y VALIENTE, J., “Cástulo III». E.A.E. 117, 1981 págs. 208-210. 
Arcilla ocre claro. Incompleta.

Procedencia: Desconocida.

Al igual que la anterior la encontramos en la Alcudia de Elche ${ }^{58}$ y Cástulo ${ }^{59}$.

Cronologia: A partir del siglo iv a.C. hasta el IV d.C.

Bibliografia: Inédito.

15. N. ${ }^{\circ} 904$; barro cocido; $0,04 \times 0,07 \times 0,02 \mathrm{~m}$

Lucerna de pico redondeado, canal largo y abierto, que une la zona del pico con el disco, separando una orla decorada por una banda de surcos de hojas de laurel, interrumpida por el asa y la ancha acanaladura del pico. En el disco dos palmas encerrando un motivo rectangular, realizado con la misma técnica de surcos, donde se aprecia dos orificios. En la base un círculo inciso y abierto, del que parte tres incisiones, siendo las dos laterales continuación de la circunferencia.

Arcilla ocre claro. Incompleta, le falta parte del disco.

Procedencia: Desconocida.

Esta lucerna es del tipo XXXI de Corinto, fechado entre los siglos IV $y \vee$ d. $C^{60}$ y del tipo IV de la Mauretania Tingitania del siglo Iv d. C. ${ }^{61}$.

Cronología: Siglo Iv d. C.

Bibliografía: Inédita.

16. Núm. Inv. 903; barro cocido; $0,05 \times 0,06 \times 0,08 \mathrm{~m}$

Lucerna semejante a la anterior, cuya orla está decorada por una banda de páteras interrumpidas, igualmente, por el asa y la ancha acanaladura del pico. En el disco el chrismon cuya $X$ sirve de trazo vertical de la $P$ cerrada. Dos orificios en diagonal.

Arcilla ocre claro. Incompleta, le falta el pico.

Procedencia: Desconocida.

${ }^{58}$ Véase nota 56

${ }^{58}$ Véase nota 57.

${ }^{60}$ Broneer, O., Terracotta Lamps. Corinth, IV. Part. II, Cambridge 1930, págs. 118119, núms. 1.451-1.500, láms. XXI-XXII.

${ }^{61}$ PonsiCH, M., Les lampes romaines en terre cuite de la Maurétanie Tingitane, Rabat 1961, págs. 35-36, láms. XXVI-XXVIII. 
El monograma con la $P$ cerrada es un motivo cristiano bastante frecuente en África ${ }^{62}$.

Cronologia: Siglo iv d. C.

Bibliografia: Inédita.

VIDRIO

17. Núm. Inv. 906; vidrio; $0,09 \times 0,01 \mathrm{~m}$

Ungüentario romano de vidrio translúcico. Borde exvasado, cuerpo tubular y base redondeada engrasada que no le permite mantenerse en pie. Color azulado. Incompleto.

Procedencia: Desconocida.

Este ejemplar se identifica con la variante $8 / 27$ de Isings ${ }^{63}$, con paralelos en el catálogo de Hayes ${ }^{64}$, fechándose en la segunda mitad 0 finales del siglo । d. C. En Ibiza existen varios ejemplares ${ }^{65}$.

Cronologia: Segunda mitad o finales del siglo । d. C.

Bibliografía: Inédito.

18. Núm. Inv. 902; vidrio, $0,10 \times 0,02 \mathrm{~m}$

Ungüentario romano de vidrio translúcido. Borde exvasado de forma acampanada, cuerpo de tendencia piriforme. Presenta un estrechamiento en su mitad, que separa el cuello del cuerpo, base ligeramente rehundida. Color verdoso incompleto.

Procedencia: Desconocida.

62 Ponsich, M., op cit., en la nota 61, págs. 60 y 63, fig. 21, núm. 366.

${ }^{63}$ IsINGS, C., "Roman glass from dated finds", Archaeologica Traiectina, II. J. B. Wolters, Cronigen-Yakarta, 1957, pág. 24.

54 HAYES, J. W., Roman and Pre-Roman Glass in the Royal Ontario Museum (A Catalogue) in the Royal Ontario Museum. Toronto 1975, págs. 150-151, fig. 20, núm. 623.

${ }_{65}$ Roman I Calvet, J., recoge una pieza de estas caracteristicas como procedente de "diversos lugares de Ibiza", Los nombres e importancias arqueologicas de las islas Pythiusas, Barcelona 1906, lám. XXX, 5; Gomez BELLARD, C., "EXcavaciones arqueológicas en el Puig des Molins (Ibiza). La campaña de 1946", E.A.E., 132, 1984 pág. 122, hipogeo 50, MAl 7331, fig. 58,4 VENTO MiR, E., op cit., en nota 52, pág. 106, fig. 39, M. E.-El/38. 
Esta forma se aproxima al tipo Isings 28 a ${ }^{66}$, con similitudes en el catálogo de Hayes ${ }^{67}$. De Ibiza conocemos un ungüentario similar en la colección Marti Esteve ${ }^{68}$.

Cronologia: Segunda mitad o finales del siglo । d. C.

Bibliografía: Inédito.

19. Núm. Inv. 898 ; vidrio; $0,13 \times 0,10 \mathrm{~m} \varnothing$

Vaso romano de vidrio translúcido. Sin borde diferenciado, de forma más o menos cónico-cilindrico, alto, con ligero perfil en $S$ presentando una decoración de gallones o costillas. Pie diferenciado (fig. 10). Color azulado. Completo.

Procedencia: Desconocida.

Esta forma se aproxima al tipo Isings $35^{69}$, difundido por todo el área mediterránea a partir del siglo I d. C.

Cronología: Siglo I d. C.

Bibliografía: Inédito.

\section{NUMISMÁTICA}

20. Núm. Inv. 1025/2; plata; $16 \mathrm{~mm} \varnothing ; 3,96$ grs

Denario romano republicano. En el anverso cabeza de Dea Roma con casco, de perfil a la izquierda; detrás del tipo, TAMP (IL); delante, una "X». En el reverso, cuadriga al galope conducida por Apolo; bajo el tipo, la leyenda Roma; en el exergo, M. BAEBI.Q. (F).

Bien conservado en general, aunque con el natural desgaste del relieve.

Procedencia: Desconocida.

60 Isings, G., op cit., en nota 63, pág. 42.

67 HAYES, J.W., op cit., en nota 64, pág. 151, fig. 20, núm. 625.

6e VeNTO MIR, E., op cit., en nota 52. pág. 108, fig. 39, M.E.-El/29.

69 Isings, G., op cit., en nota 63, pág. 49 . 


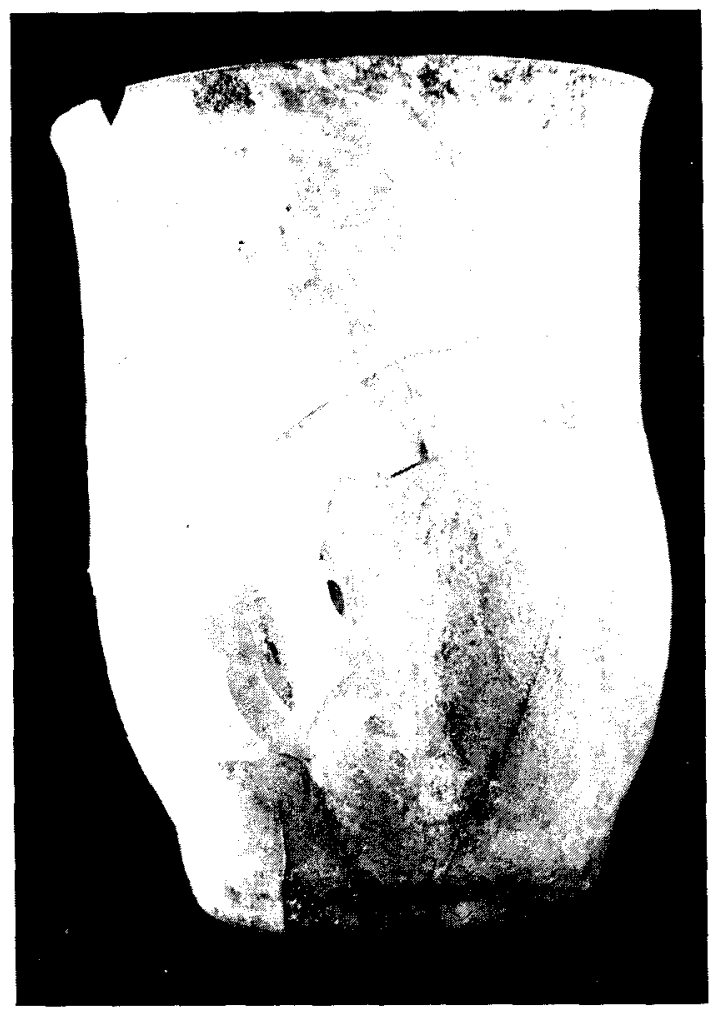

Fig. 10. Vaso romano de vidrio translucido.

El tipo ha sido catalogado con el número 935 de la colección de monedas romanas republicanas del Museo Británico ${ }^{70}$, entre los denarios acuñados por Marcus Baebius Quinti Filius Tampilus.

Cronologia: C. 150 a. C

Bibliografía: Inédito.

21. Núm. Inv. 1025/1; planta; $16 \mathrm{~mm} \varnothing ; 3,96$ grs

Denario romano republicano. En el anverso, cabeza de Dea Roma de perfil a la derecha; frente al tipo de la leyenda Roma; detrás, la marca

${ }^{30}$ Grveber, H. A., A Catalogue of the Roman coins in the British Museum, Londres 1910, t.I, pág. 133, lám. XXVI, 9. 
de valor, una "X». En el reverso, cuadriga de caballos al paso conducida por Apolo portador de palma; en el exergo, CN. DOMI. Bien conservado en general.

Procedencia: Desconocida.

Tiene un paralelo en el denario acuñado por Quintus Caecilius Metellus en la misma época en que realiza sus acuñaciones Cnaeus Domitius Ahenobarbus ${ }^{71}$.

Cronologia: Acuñado por Cnaeus Domitius Ahenobarbus entre 124103 a. C.

Bibiliografía: Inédito.

71 Grveber, H. A., op. cit., en nota 70. t. I, pág. 156, lám. XXVIII, 18. 